\title{
UV SPECTROPHOTOMETRIC METHODS FOR THE SIMULTANEOUS DETERMINATION OF AMOXICILLIN AND FLUCLOXACILLIN.
}

\author{
BY \\ Maya Shaaban Eissa ${ }^{1}$, Eman Darweish ${ }^{1 *}$, Mohammed Refaat Elghobashy ${ }^{2}$, Mostafa \\ Abdelaty Shehata ${ }^{2}$.

\section{FROM} \\ ${ }^{1}$ Analytical Chemistry Department, Faculty of Pharmacy, Egyptian Russian University, \\ Badr City, Cairo, Egypt. \\ ${ }^{2}$ Analytical Chemistry Department, Faculty of Pharmacy, Cairo University, Kasr El- \\ Aini street, Cairo, Egypt.
}

\begin{abstract}
Spectrophotometric methods were introduced for the simultaneous determination of Amoxicillin (AMX) and flucloxacillin(FLX) in their pure forms and capsules pharmaceutical formulations. The first method was ratio difference (RD), in which the amplitude difference between 238 and $255 \mathrm{~nm}$ for AMX and between 254 and $238 \mathrm{~nm}$ for FLX were measured.The second one was mean centering of ratio spectra (MCR) in which the peak amplitude at 286nm for the determination of AMX and the peak amplitude at $236 \mathrm{~nm}$ for the estimation of FLX were measured. The third method was Area under the curve (AUC) where the range of 226 and $236 \mathrm{~nm}$ were adopted for AMX determination and of 240 and $247 \mathrm{~nm}$ for FLX determination. All of the previous methods were successfully used for quantitation of AMX and FLX in concentration ranges of $5-50 \mu \mathrm{g} / \mathrm{ml}$ and $10-70 \mu \mathrm{g} / \mathrm{ml}$, respectively by RD and MCR methods and of 10$60 \mu \mathrm{g} / \mathrm{ml}$ and $10-70 \mu \mathrm{g} / \mathrm{ml}$, respectively for AMX and FLX by AUC method. All of the developed methods were validated using ICH guidelines and statistically compared to a reported method. The adopted methods can be applied for the regular analysis of AMX and FLX mixture in QC laboratories.
\end{abstract}

\section{Keywords}

Amoxicillin (AMX), Flucloxacillin (FLX), Ratio difference (RD), mean centering MCR, Area Under The Curve(AUC).

*Corresponding author: e-mail: emy89_2009@hotmail.com. 


\section{INTRODUCTION}

Amoxicillin (AMX), (6R)-6-[ $\alpha$-D-(4-hydroxyphenyl) glycylamino] penicillanic acid Fig. 1(a) [M.J. O'Neil, 2006], consider one of the most important frequently used $\beta$ lactam antibiotics in the world. It is used to treat humans and animals(B.G. Katzung, 2004; M.J. O'Neil, 2006; S.C. Sweetman, 2002.).Flucloxacillin (FLX), (6R)-6-[3-(2chloro-6-fluorophenyl)-5-methylisoxazole-carboxamido] penicillanic acid Fig. 1(b) [M.J. O'Neil, 2006]. It is a bactericidal agent used mostly (B.G. Katzung, 2004; M.J. O'Neil, 2006; S.C. Sweetman, 2002.)for the treatment of infections due to staphylococci resistant to treatment by benzyl penicillin .Few methods were reported for determination of both components including spectrophotometry(Attia et al, 2016a; Mohamed, Salem et al, 2007), HPLC (Aly et al, 2007; Liu et al, 2005; Nikam et al, 2009; Shanmugasundaram et al., 2009)], and chemommetric assisted techniques (Attia et al, 2016b; Mohamed et al., 2007). The presented methods have the advantage of being easier, economic, rapid and selective than other reported methods.Also they have the ability to separate Amoxicillin and Flucloxacillin without interference from each other or from capsule excipients.

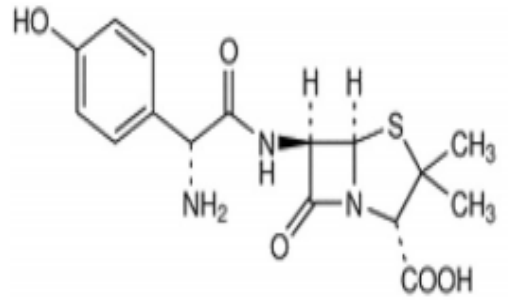

(a)

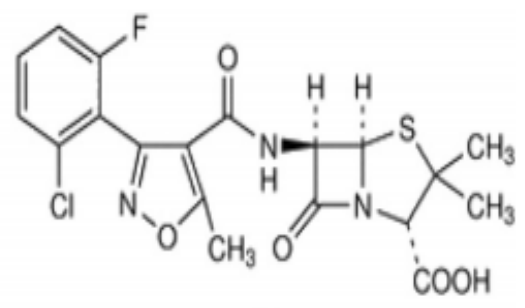

(b)

Figure 1: Chemical structure of Amoxicillin (a) and Flucloxacillin (b)

\section{Experimental}

\subsection{Materials and Reagents}

A. pure standards: Amoxicillin certified to contain (99.86\%) and Flucloxacillin certified to contain (99.78\%); kindly supplied by EIPICO pharmaceutical Company, Tenth of Ramadan City, Egypt.

The purity of the supplied standards was assured by applying the reported method (Nikam et al., 2009). Pharmaceutical preparation: Flumox 500® Capsules; labeled to contain 250mgof each of AMX and FLX ,batch number 1702653, manufactured by EIPICO pharmaceutical Company, Tenth of Ramadan City Egypt.

C) Methanol $\left(\right.$ Piochem $^{\circledR}$ ) spectroscopic grade and distilled water.

\subsection{Instruments}

JASCO dual beam (Japan) UV-visible spectrophotometer model V-630. 
The bundle software, spectra manager II was used. The spectral slit width was $2 \mathrm{~nm}$ and scans speeds $1000 \mathrm{~nm} / \mathrm{min}$.

Mean centering was done with a written code in Matlab7.10.0.499 (R2010a).

\subsection{Preparation of standard solutions.}

AMX standard stock solution: $1 \mathrm{mg} \mathrm{mL}^{-1}$ in methanol.

FLX standard stock solution: $1 \mathrm{mg} \mathrm{mL}^{-1}$ in methanol.

\subsection{Procedure.}

Standard serial dilutions of both AMX and FLX were prepared separately from their standard stock solutions $1 \mathrm{mg} \mathrm{mL}^{-1}$ using methanol as a solvent to obtain the final concentration 5-60 and $10-70 \mu \mathrm{g} / \mathrm{ml}$ for AMX and FLX ,respectively. Then the zero order of absorption spectra were recorded after scanning them at 200-400nm using methanol as blank and stored in the computer.

\subsubsection{Construction of calibration curves.}

\section{Ratio Difference Method (RD).}

The stored zero order spectrum for each concentration of AMX was divided by $50 \mu \mathrm{g} / \mathrm{mL}$ of FLX as divisor and for each concentration of FLX was divided by $50 \mu \mathrm{g}$ $/ \mathrm{ml}$ of AMX as divisor. The obtained ratio spectra were used to develop RD calibration curves for AMX and FLX by plotting the amplitude difference of ratio spectra between 238 and $255 \mathrm{~nm}$ for AMX and at 238and $254 \mathrm{~nm}$ for FLX against their corresponding concentrations in $\mu \mathrm{g} / \mathrm{mL}$ and the regression equations were then computed.

\section{Mean Centering Ratio (MCR).}

The ratio spectra mentioned previously in the range of 200-400 $\mathrm{nm}$ were mean centered and the calibration curves were constructed by plotting the peak amplitude at 286nm for AMX and the amplitude at $236 \mathrm{~nm}$ for FLX against their corresponding concentrations.

\section{Area under the curve (AUC).}

The AUC of AMX was measured between (226-236) nm for AMX and between (240 -247) $\mathrm{nm}$ for FLX. The calibration curve of the mentioned drugs was plotted relating area under the curve versus the corresponding concentrations of AMX and FLX, and then the regression equations and the absorptivity constants were computed.

\subsection{Application to Laboratory Prepared Mixtures}

In two series of 10-mL volumetric flasks, aliquots of AMX and FLX standard solutions were transferred to prepare mixtures with different ratios of the two drugs then, the volume was completed with methanol. The spectra of the prepared mixture were recorded. The concentrations of AMX and FLX were calculated using the corresponding regression equations for each method.

\subsection{Application to Pharmaceutical Preparation}

Content of ten Flumox $500 \circledR$ capsules were weighed and well mixed. A portion of this powder equivalent to $10 \mathrm{mg}$ of both AMX and FLX was weighed and transferred into $100-\mathrm{mL}$ volumetric flask to dissolve it in $75 \mathrm{~mL}$ of methanol. The solution was shaken vigorously for $20 \mathrm{~min}$ then sonicated for $25 \mathrm{~min}$. The volume was adjusted to 
$100 \mathrm{~mL}$ with methanol and filtered. Aliquots of filtrate were diluted with methanol to have different concentrations of AMX and FLX samples as mentioned under linearity. To evaluate the accuracy of the developed method, standard addition technique was applied.

\section{Results and Discussion}

The developed methods were applied to resolve the spectral overlap of AMX and FLX in their binary mixture, as shown in Figure 2 without previous separation steps.

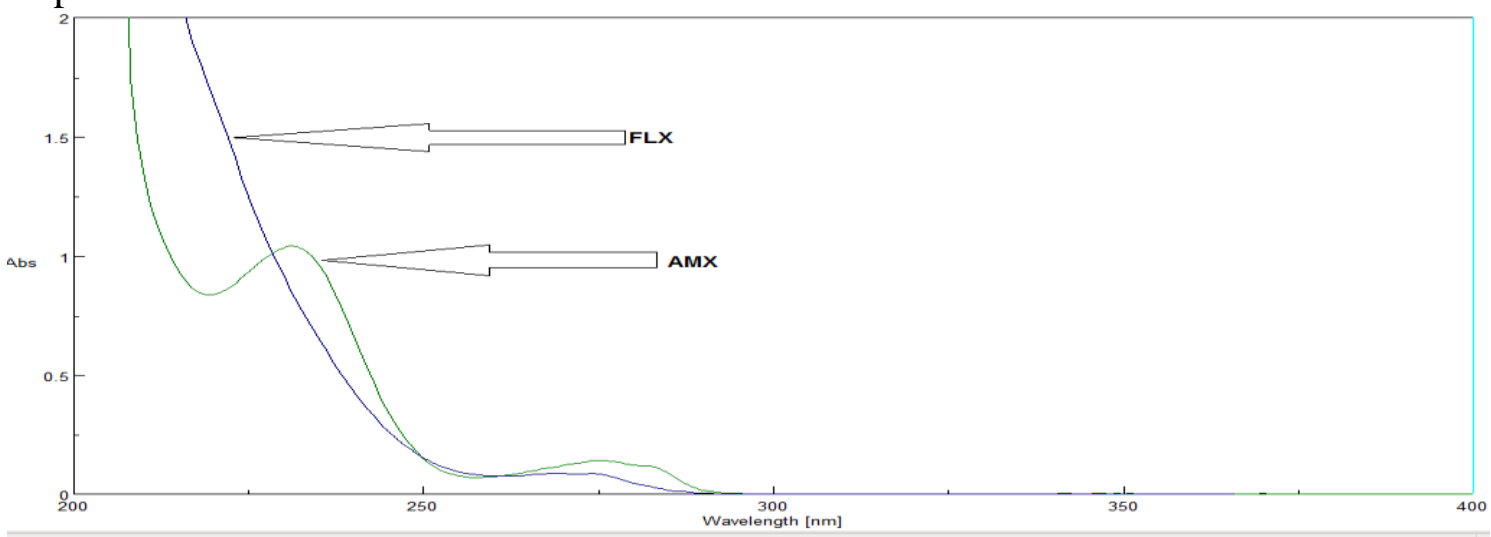

Figure 2 Zero order absorption spectra of AMX $(50 \mu \mathrm{g} / \mathrm{ml})$ and FLX $(50 \mu \mathrm{g} / \mathrm{ml})$ in methanol.

\subsection{Method development and optimization.}

\section{Ratio Difference Method}

This method is simple, accurate include two essential steps; first one is to select appropriate divisor. After trying different divisors, the best results in according to accuracy and precision showed that the divisor of choice was $50 \mu \mathrm{g} / \mathrm{mL}$ of AMX and $50 \mu \mathrm{g} / \mathrm{mL}$ of FLX. The absorption spectra of each drug were divided by the chosen divisor. The second important step is how to choose the most suitable wavelengths at which the measurements will be recorded (Lamie, 2015). The selected wavelengths, in the ratio spectra should have distinct difference in amplitudes as shown in Figure 3and Figure 4. In order to reveal a good linearity, many pairs of wavelengths were tested, and according to this, wave lengths 238 and $255 \mathrm{~nm}$ for AMX, and wave lengths of 254 and $238 \mathrm{~nm}$ were selected for FLX. Their linear regression equations were then computed.

$$
\begin{array}{lc}
\Delta \mathrm{P}_{\text {AMX }}=0.0297 \mathrm{C}-0.0455 & \mathrm{r}=0.9996 \\
\Delta \mathrm{P}_{\text {FLX }}=0.0088 \mathrm{C}-0.0163 & \mathrm{r}=0.9997
\end{array}
$$

Where $\Delta \mathrm{P}$ express the difference of peak amplitude of the ratio difference spectrum curve, $\mathrm{C}$ is concentration of drug in $\mu \mathrm{g} / \mathrm{mL}$ and $\mathrm{r}$ is the correlation coefficient. 


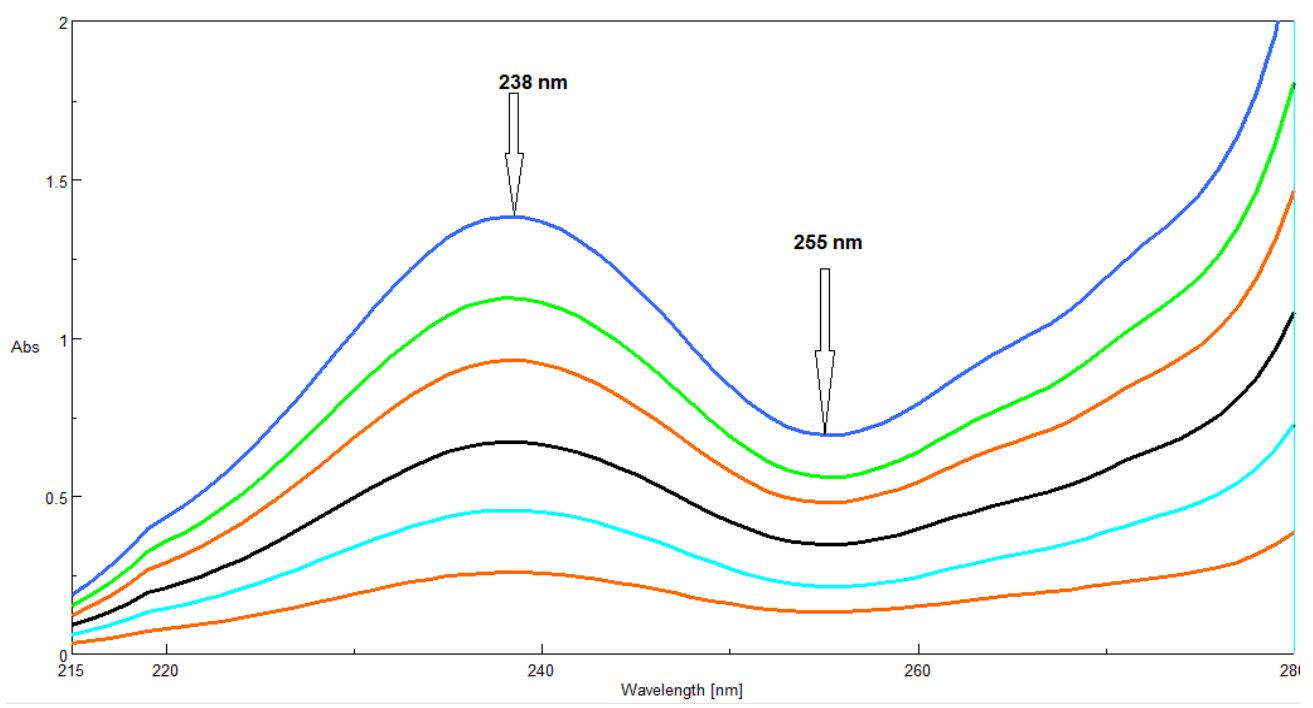

Figure 3 Ratio spectra of $(5-50 \mu \mathrm{g} / \mathrm{mL})$ AMX using FLX $(50 \mu \mathrm{g} / \mathrm{mL})$ as divisor

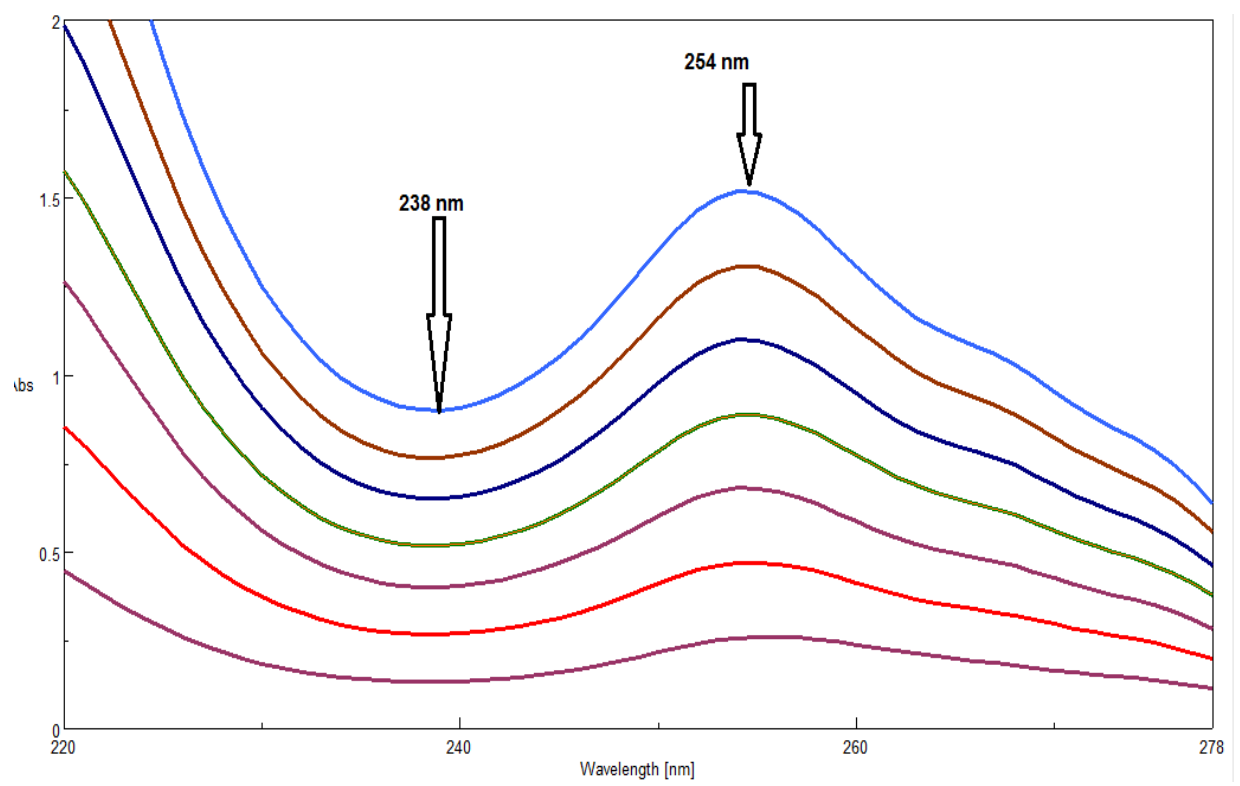

Figure 4 Ratio spectra of $(10-70 \mu \mathrm{g} / \mathrm{mL})$ FLX using AMX $(50 \mu \mathrm{g} / \mathrm{mL})$ as divisor.

\section{Mean Centering Method}

This method is of a great advantage in that; it can minimize noise in ratio spectra and enhance sensitivity. This is due to mean centering of the ratio spectra (Afkhami et al, 2005, 2006) in the range of 200-400nm as in Figure 5 and Figure 6 after using $50 \mu \mathrm{g} / \mathrm{ml}$ as a divisor to each drug as previously discussed under RD method .The concentrations of AMX and FLX can be determined without prior separation at $286 \mathrm{~nm}$ for AMX nm and at $236 \mathrm{~nm}$ for FLX.

Regression equations were then computed.

$\mathbf{M C R}_{\mathrm{AMX}}=0.0366 \mathrm{C}+0.3720 \quad \mathrm{r}=0.9999$

$\mathbf{M C R}_{\mathrm{FLX}}=0.0048 \mathrm{C}+0.0003 \quad \mathrm{r}=0.9995$

Where MCR represents the peak amplitude of the mean centered ratio spectrum curve, $\mathrm{C}$ express concentration and $\mathrm{r}$ express the correlation coefficient. 


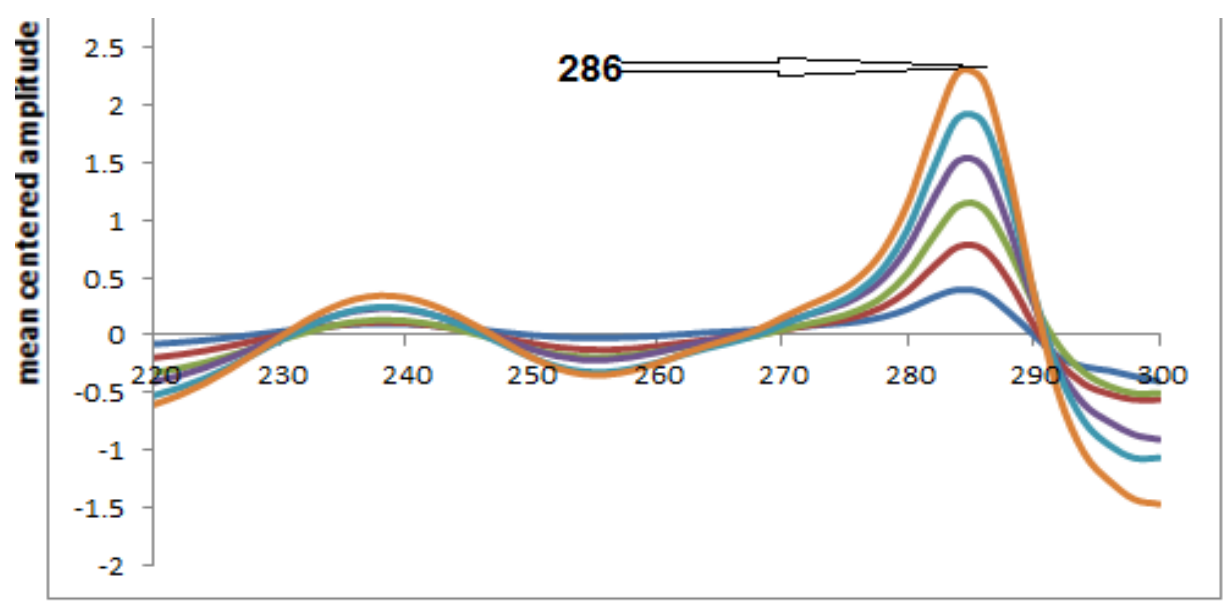

Wave length $\mathbf{n m}$

Figure 5 MCR spectra of AMX $(5-50 \mu \mathrm{g} / \mathrm{mL})$ using FLX $(50 \mu \mathrm{g} / \mathrm{mL})$ as a divisor.

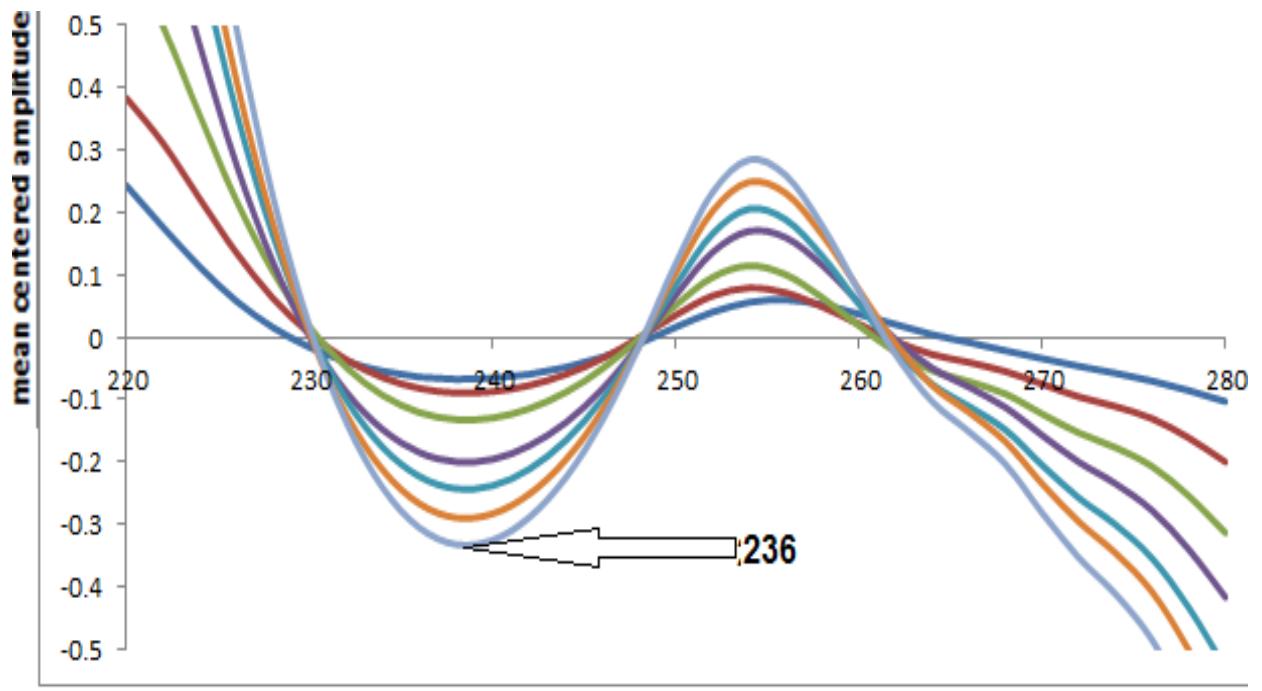

wave length $\mathrm{nm}$

Figure 6 MCR of FLX $(10-70 \mu \mathrm{g} / \mathrm{mL})$ using AMX $(50 \mu \mathrm{g} / \mathrm{mL})$ as a divisor.

\section{Area under the curve method (AUC)}

AUC (Abdelrahman, 2013) was reported to be used for the simultaneous determination of components having over lain spectra in binary mixtures by calculating the areas under the spectra in relation to their concentrations. Area under the curves obtained from the scanned spectra over the ranges of wavelengths (226 - 236) and (240 - 247) $\mathrm{nm}$ for the two drugs, Figure 7 and Figure 8 were recorded and then the corresponding regression equations were obtained for both AMX and FLX.

For AMX:

$$
Y_{(226-236)}=0.2512 x-0.059 \quad(r=0.9996) .
$$




$$
Y_{(240-247)}=0.0763 x+0.039 \quad \quad(r=0.9995) .
$$

For FLX:

$$
\begin{array}{lr}
Y_{(226-236)}=0.0515 x-0.1409 & (r=0.9996) . \\
Y_{(240-247)}=0.2096 x-0.2651 & (r=0.9996) .
\end{array}
$$

Where $\boldsymbol{y}$ is the area under curve over the ranges (226-236) and (240-247) $\mathrm{nm}$ respectively, $\boldsymbol{x}$ is the concentration in $\mu \mathrm{g} / \mathrm{mL}$ and $\boldsymbol{r}$ is the correlation coefficient

Areas under the curve and the absorptivity values at the selected wavelength ranges are used for calculating the concentration of AMX in presence of FLX and vice versa using the following equations:

$$
\begin{aligned}
& C^{X}=\frac{\left(\begin{array}{lll}
a^{Y}{ }_{\lambda 1-\lambda 2} A U C_{\lambda 3-\lambda 4}
\end{array}\right)-\left(\begin{array}{ll}
a^{Y}{ }_{\lambda 3-\lambda 4} & A U C_{\lambda 1-\lambda 2}
\end{array}\right)}{\left(\begin{array}{lll}
a^{Y}{ }_{\lambda 1-\lambda 2} & a^{X}{ }_{\lambda 3-\lambda 4}
\end{array}\right)-\left(\begin{array}{ll}
a^{Y}{ }_{\lambda 3-\lambda 4} & a^{X} \lambda 1-\lambda 2
\end{array}\right)} \\
& C^{Y}=\frac{\left(\begin{array}{lll}
a_{\lambda 1-\lambda 2} & A U C_{\lambda 3-\lambda 4}
\end{array}\right)-\left(\begin{array}{ll}
a_{\lambda 3-\lambda 4} & A U C_{\lambda 1-\lambda 2}
\end{array}\right)}{\left(\begin{array}{lll}
a_{\lambda 1-\lambda 2}^{Y} & \left.a^{X}{ }_{\lambda 3-\lambda 4}\right)-\left(a^{Y}{ }-\lambda 4\right. & a^{X}{ }_{\lambda 1-\lambda 2}
\end{array}\right)}
\end{aligned}
$$

- Where $\mathrm{C}^{\mathrm{X}}, \mathrm{CY}$ are the concentrations of the cited drugs.

- $a_{\lambda 1-\lambda 2}^{X}, a^{X}{ }_{\lambda 3-\lambda 4}$ are the absorptivity of drug $\mathrm{X}$ at $(\lambda 1-\lambda 2) \mathrm{nm}$ and at $(\lambda 3-\lambda 4) \mathrm{nm}$

, Respectively.

- $a_{\lambda 1-\lambda 2,}^{Y} a_{\lambda 3-\lambda 4}^{Y}$ are the absorptivity of drug $Y$ at $(\lambda 1-$ $\lambda 2) n m$ and at $(\lambda 3-\lambda 4) n m$, respectively.

- $A U C_{\lambda 1-\lambda 2} A U C_{\lambda 3-\lambda 4}$ are the area under the curves at $(\lambda 1-\lambda 2) \mathrm{nm}$ and at $(\lambda 3-\lambda 4) \mathrm{nm}$, respectively .

The calibration graphs that relate the measured areas under the curve to the concentration of each component in $\mu \mathrm{g} / \mathrm{mL}$ were constructed. 


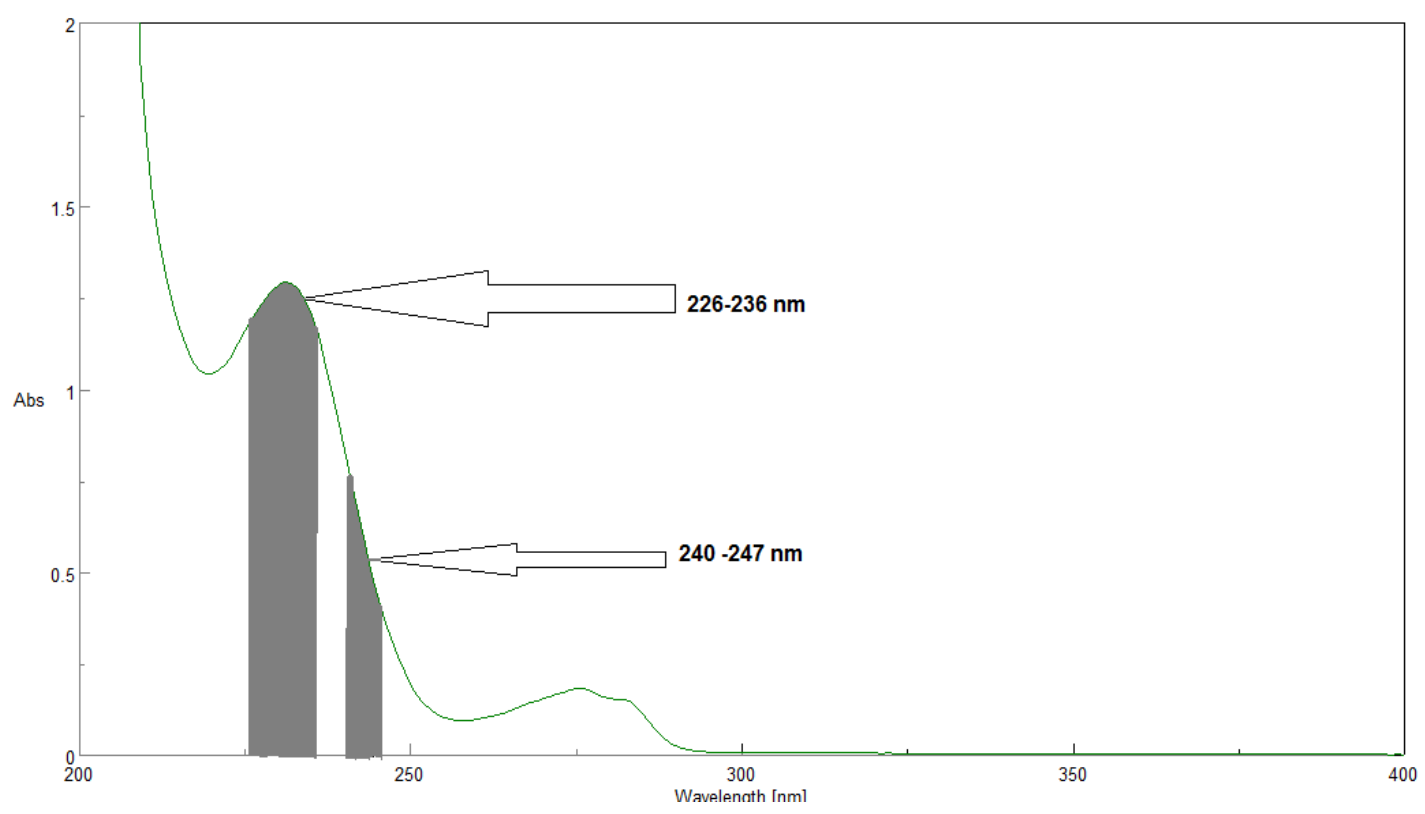

Figure 7 Zero order absorption spectrum of AMX $(50 \mu \mathrm{g} / \mathrm{ml})$ showing area under the curve over the ranges (226-236) and (240-247) $\mathrm{nm}$.

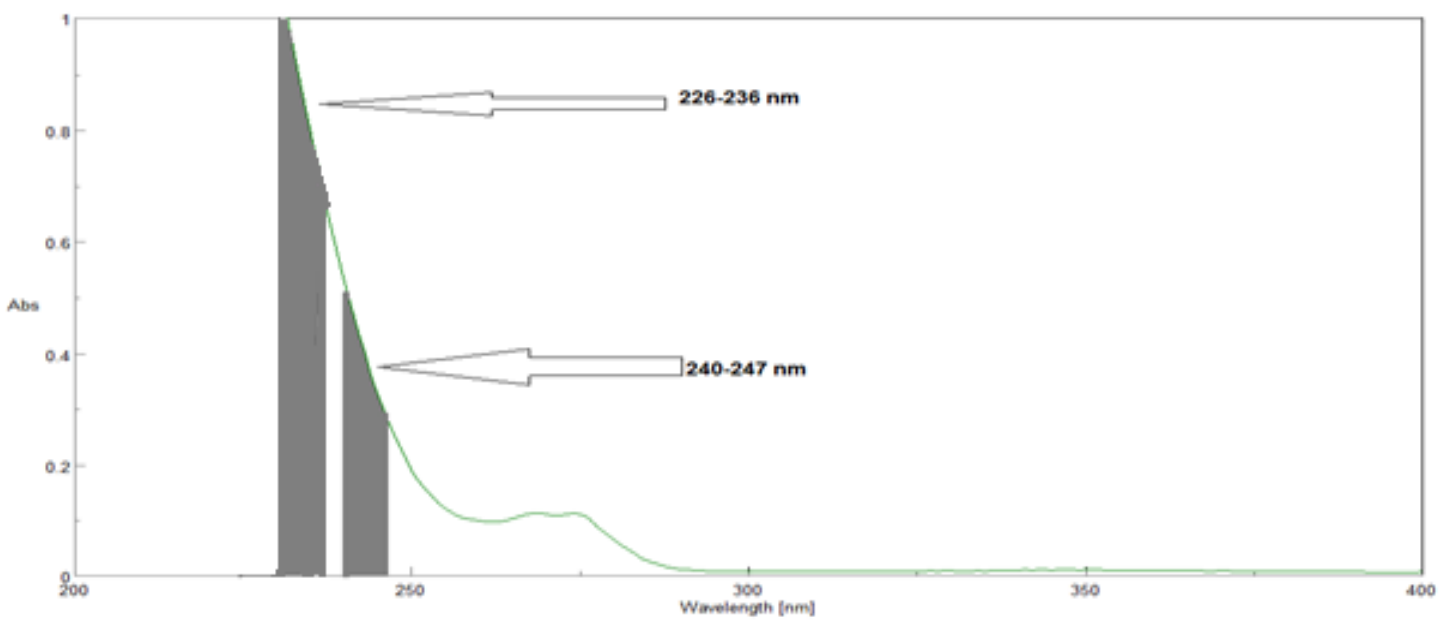

Figure 8 Zero order absorption spectrum of FLX $(50 \mu \mathrm{g} / \mathrm{ml})$ showing area under the curve over the ranges (226-236) and (240-247) $\mathrm{nm}$.

\subsection{Validation of the Methods}

The developed methods were validated according to ICH recommendations (Ich, 2005)

\section{Linearity and range}

Methods linearity could be estimated by analyzing seven concentrations .All of the previous methods determined successfully AMX and FLX in concentration ranges of $5-50 \mu \mathrm{g} / \mathrm{ml}$ and $10-70 \mu \mathrm{g} / \mathrm{ml}$, for RD and MCR methods and of $10-60 \mu \mathrm{g} / \mathrm{ml}$ and $10-$ $70 \mu \mathrm{g} / \mathrm{ml}$, for AMX and FLX respectively by AUC method. The high values of the determination coefficients and the low intercept value indicate the excellent linearity of 
the developed methods. Linearity range, regression equation, intercept, slope and the determination coefficient for calibration data were presented in Table 1.

\section{Accuracy}

The accuracy of the developed methods was evaluated by applying five different concentrations of every drug with in linear range in which good percentage recoveries for the developed methods was found where \% R of AMX was in the range100.11$100.15 \%$ and for FLX 99.93-100.11\% as mentioned in Table 1.

\section{Precision}

Precision of the developed methods was estimated by applying intra-day and inter-day precision in triplicate using three different concentrations of $(15,25$ and 35 $\mu \mathrm{g} / \mathrm{mL})$ for AMX and $(20,40$ and $60 \mu \mathrm{g} / \mathrm{mL})$ for FLX either on the same day or on three different days then the relative standard deviations were calculated as presented in Table 1 .

\section{Selectivity}

The selectivity of the developed methods evaluated by analysis of laboratory prepared mixtures of AMX and FLX in different ratios whose concentration were inside the linear range where $\% \mathrm{R} \pm \mathrm{RSD}$ were found to be $98.86-101.87 \pm 0.366-0.989$ Satisfactory results were obtained as illustrated in Table 2.

\section{Limit of detection (LOD) and Limit of quantification (LOQ).}

The LOD and LOQ of the developed methods were calculated using standard deviation $(\sigma)$ of the response and the slope of the calibration curve (S) as shown in the following equations:

$\mathrm{LOD}=3.3 \times \sigma / \mathrm{S}, \mathrm{LOQ}=10 \times \sigma / \mathrm{S}$ and their results were shown in Table1.

\subsection{Application of the methods in assay of capsule.}

The adopted methods were applicable for the analysis of AMX and FLX in their combined pharmaceutical formulation Flumox $500{ }^{\circledR}$ tablet with no interference from the excipients; the validity of the adopted methods was checked by applying standard addition technique, where satisfactory results were obtained. The results were shown in Table 3 .

\subsection{Statistical analysis.}

The results obtained from statistical comparison between the developed methods and the reported HPLC method (Sebaiy et al, 2011) show no significant differences as presented in Table 4 because the calculated $\mathrm{t}$ and $\mathrm{F}$ values were less than the theoretical ones .

It was found that these developed methods were more simple and faster than the reported one.

The reported method used in comparison instead of the official method as it gives the opportunity to determine the concentration of every component in presence of the other.

\section{Conclusion}

The developed methods were concerned for simultaneous determination of AMX and FLX in the pure form or in its pharmaceutical preparation. The adopted UV 
spectrophotometric methods were considered to be simple, specific, convenient, economic, time saving. The suggested methods showed high sensitivity, specificity as it can determine AMX and FLX without any interference of additives and excipients. Also these adopted methods were inexpensive and simple without any sophisticated instruments or techniques. The adopted methods can be easily applied in quality control laboratories without preliminary separation.

Table1. Regression parameters and results of determination of pure samples of AMX and FLX by the developed uv spectrophotometric methods

\begin{tabular}{|c|c|c|c|c|c|c|c|c|}
\hline \multirow{3}{*}{$\begin{array}{c}\text { Parameter } \\
\begin{array}{c}\text { wavelength } \\
\text { selected(nm) }\end{array}\end{array}$} & \multicolumn{2}{|c|}{ RD } & \multicolumn{2}{|c|}{ MCR } & \multicolumn{4}{|c|}{ AUC } \\
\hline & \multirow{2}{*}{$\begin{array}{c}\text { AMX } \\
\text { At } \Delta \mathbf{p}= \\
238-254\end{array}$} & \multirow{2}{*}{$\begin{array}{c}\text { FLX } \\
\text { At } \Delta p= \\
254-238\end{array}$} & \multirow{2}{*}{$\begin{array}{l}\text { AMX } \\
\text { P } 286\end{array}$} & \multirow{2}{*}{$\begin{array}{l}\text { FLX } \\
\text { P 236 }\end{array}$} & \multicolumn{2}{|c|}{ AMX } & \multicolumn{2}{|c|}{ FLX } \\
\hline & & & & & 226-236 & 240-247 & 226-236 & $240-247$ \\
\hline $\begin{array}{c}\text { Accuracy }{ }^{\mathrm{a}} \\
(\text { Mean } \pm \text { RSD })\end{array}$ & $\begin{array}{l}100.15 \\
\pm 0.538\end{array}$ & $\begin{array}{l}100.11 \\
\pm 0.516\end{array}$ & $\begin{array}{l}100.03 \\
\pm 0.870\end{array}$ & $\begin{array}{c}99.93 \\
\pm 0.710\end{array}$ & \multicolumn{2}{|c|}{$100.11 \pm 1.448$} & \multicolumn{2}{|c|}{$99.98 \pm 0.836$} \\
\hline \multicolumn{9}{|l|}{ Precision } \\
\hline $\begin{array}{l}\text { Repeatability } \\
(\text { RSD })^{\text {b }}\end{array}$ & 0.658 & 0.469 & 1.095 & 1.010 & \multicolumn{2}{|r|}{0.868} & \multicolumn{2}{|r|}{0.624} \\
\hline $\begin{array}{c}\text { Intermediate } \\
\text { Precision(RSD) }\end{array}$ & 0.661 & 0.875 & 0.728 & 0.659 & \multicolumn{2}{|r|}{1.314} & \multicolumn{2}{|r|}{0.646} \\
\hline \multicolumn{9}{|l|}{ Linearity } \\
\hline Range $(\mu \mathrm{g} / \mathrm{ml})$ & $5-50$ & $10-70$ & $5-50$ & $10-70$ & \multicolumn{2}{|r|}{$10-60$} & \multicolumn{2}{|r|}{$10-70$} \\
\hline $\begin{array}{l}\text { Correlation } \\
\text { Coefficient }\end{array}$ & 0.9996 & 0.9997 & 0.9999 & 0.9995 & 0.9996 & 0.9995 & 0.9996 & 0.9996 \\
\hline Slope & 0.030 & 0.009 & 0.0366 & 0.0048 & 0.2512 & 0.7630 & 0.2096 & 0.0515 \\
\hline Intercept & 0.045 & 0.016 & 0.3720 & 0.0003 & 0.059 & 0.039 & 0.2651 & 0.1409 \\
\hline $\operatorname{LOD}(\mu \mathrm{g} / \mathrm{ml})$ & 1.63 & 1.72 & 0.50 & 2.07 & 1.93 & 2.03 & 1.86 & 1.82 \\
\hline LOQ $(\mu \mathrm{g} / \mathrm{ml})$ & 4.95 & 5.21 & 1.53 & 6.27 & 5.84 & 6.14 & 5.64 & 5.52 \\
\hline
\end{tabular}

a average of three determinations

b The intraday, average of three concentrations repeated three times within the day.

c The interday, average of three concentrations repeated three times in three days. 
Table 2. Determination of the studied drugs in the laboratory prepared mixtures.

\begin{tabular}{|c|c|c|c|c|c|c|c|}
\hline \multirow[t]{2}{*}{ AMX } & \multirow[t]{2}{*}{ FLX } & \multicolumn{2}{|c|}{$\mathrm{RD}$} & \multicolumn{2}{|c|}{ MCR } & \multicolumn{2}{|c|}{ AUC } \\
\hline & & \multicolumn{2}{|c|}{ Recovery \% } & \multicolumn{2}{|c|}{ Recovery \% } & \multicolumn{2}{|c|}{ Recovery \% } \\
\hline \multicolumn{2}{|c|}{$\begin{array}{l}\text { Concentration } \\
(\mu \mathrm{g} / \mathrm{mL})\end{array}$} & AMX & FLX & AMX & FLX & AMX & FLX \\
\hline & & $\begin{array}{l}\text { At } \Delta p= \\
238-255\end{array}$ & $\begin{array}{l}\text { At } \Delta p= \\
254-238\end{array}$ & At $p=286$ & $\begin{array}{l}\text { At } \\
p=236\end{array}$ & & \\
\hline 10 & 15 & 99.75 & 100.32 & 99.25 & 101.42 & 101.13 & 99.62 \\
\hline 10 & 10 & 99.86 & 99.95 & 98.86 & 99.05 & 98.86 & 99.95 \\
\hline 20 & 10 & 100.64 & 99.68 & 100.14 & 99.98 & 100.14 & 98.68 \\
\hline 10 & 20 & 99.92 & 100.63 & 99.52 & 100.73 & 99.52 & 101.63 \\
\hline \multirow[t]{3}{*}{15} & 10 & 101.87 & 99.71 & 100.87 & 100.95 & 100.87 & 99.31 \\
\hline & Mean & 100.41 & 100.06 & 99.95 & 100.43 & 100.10 & 99.84 \\
\hline & SD & 0.889 & 0.366 & 0.720 & 0.830 & 0.939 & 0.989 \\
\hline
\end{tabular}

Table 3.Determination of AMX and FLX in Flumox 500 capsules by the developed uv spectophotometric method and application of standard addition technique

\begin{tabular}{|l|l|l|l|l|}
\hline & \multicolumn{2}{|l|}{$\begin{array}{l}\text { Pharmaceutical } \\
\text { Preparation } \\
(\text { Recovery \% } \pm \text { SD)* }\end{array}$} & \multicolumn{2}{l|}{$\begin{array}{l}\text { Standard Addition } \\
(\text { Recovery \% } \pm \text { SD)** }\end{array}$} \\
\hline & AMX & FLX & AMX & \multicolumn{1}{l|}{} \\
\hline $\begin{array}{l}\text { Ratio } \\
\text { Difference }\end{array}$ & $100.23 \pm 0.716$ & $100.84 \pm 0.888$ & $100.11 \pm 1.319$ & $100.99 \pm 0.860$ \\
\hline $\begin{array}{l}\text { Mean } \\
\text { centering }\end{array}$ & $100.53 \pm 0.557$ & $100.50 \pm 0.555$ & $99.85 \pm 1.437$ & $101.21 \pm 1.021$ \\
\hline AUC & $100.44 \pm 0.658$ & $100.94 \pm 0.458$ & $100.11 \pm 1.491$ & $101.03 \pm 0.673$ \\
\hline
\end{tabular}

*Average of six determinations.

**Average of nine determinations over three concentration levels.

Table 4. Statistical analysis of the developed UV spectrophotometric methods and the reported method of AMX and FLX in their pharmaceutical dosage form 


\begin{tabular}{|c|c|c|c|c|}
\hline \multicolumn{5}{|l|}{ AMX } \\
\hline Parameter & RD & MCR & AUC & $\begin{array}{l}\quad \text { reported } \\
\text { methodc(Nikam et }(\text { ik } \\
\text { al., 2009) }\end{array}$ \\
\hline Mean \% ${ }^{a}$ & 100.23 & 100.53 & 99.13 & 100.85 \\
\hline SD & 0.716 & 0.557 & 0.658 & 0.755 \\
\hline Variance & 0.513 & 0.31 & 0.433 & 0.57 \\
\hline $\begin{array}{l}\text { t-test } \\
(2.23)^{b}\end{array}$ & 1.46 & 0.84 & 1.15 & \\
\hline $\begin{array}{l}F \\
(5.05)^{b}\end{array}$ & 1.27 & 1.26 & 1.07 & \\
\hline \multicolumn{5}{|l|}{ FLX } \\
\hline Parameter & RD & MCR & AUC & $\begin{array}{l}\text { reported } \\
\text { methodc(Nikam } \\
\text { et al., 2009) }\end{array}$ \\
\hline Mean $\%^{a}$ & 100.84 & 100.5 & 100.94 & 101.08 \\
\hline SD & 0.888 & 0.555 & 0.458 & 0.832 \\
\hline Variance & 0.789 & 0.308 & 0.21 & 0.692 \\
\hline $\begin{array}{l}\text { t-test } \\
(2.23)^{b}\end{array}$ & 0.69 & 1.42 & 0.36 & \\
\hline $\begin{array}{l}\text { F } \\
(5.05)^{b}\end{array}$ & 1.14 & 2.25 & 3.30 & \\
\hline
\end{tabular}

a Average of six experiments. $(n=6)$

b Figures between parentheses represent the corresponding tabulated values of $t$ and $\mathrm{F}$ at $\mathrm{P}=0.05$

c HPLC reported method using potassium dihydrogen orthophosphate and acetonitrile $75: 25$ as a mobile phase, column $C_{18}$ and detection at was $225 \mathrm{~nm}$ (Nikam et al., 2009) .

\section{REFRENCES}

Abdelrahman, M. M. (2013). Simultaneous determination of Cinnarizine and Domperidone by area under curve and dual wavelength spectrophotometric methods. Spectrochimica Acta Part A: Molecular and Biomolecular Spectroscopy, 113, 291-296. 
Afkhami, A., \& Bahram, M. (2005). Mean centering of ratio spectra as a new spectrophotometric method for the analysis of binary and ternary mixtures. Talanta, 66(3), 712-720.

Afkhami, A., \& Bahram, M. (2006). A novel spectrophotometric method for the simultaneous kinetic analysis of ternary mixtures by mean centering of ratio kinetic profiles. Talanta, 68(4), 1148-1155.

Aly, H. M., \& Amin, A. S. (2007). Utilization of ion exchanger and spectrophotometry for assaying amoxycillin and flucloxacillin in dosage form. International journal of pharmaceutics, 338(1), 225-230.

Attia, K. A., Nassar, M. W., El-Zeiny, M. B., \& Serag, A. (2016a). Different spectrophotometric methods applied for the analysis of binary mixture of flucloxacillin and amoxicillin: A comparative study. Spectrochimica Acta Part A: Molecular and Biomolecular Spectroscopy, 161, 64-69.

Attia, K. A., Nassar, M. W., El-Zeiny, M. B., \& Serag, A. (2016b). Effect of genetic algorithm as a variable selection method on different chemometric models applied for the analysis of binary mixture of amoxicillin and flucloxacillin: A comparative study. Spectrochimica Acta Part A: Molecular and Biomolecular Spectroscopy, 156, 54-62.

B.G. Katzung. ( 2004). Basic \& Clinical Pharmacology, 9th ed. McGraw-Hill,.

Ich, I. (2005). Q2 (R1): Validation of analytical procedures: text and methodology. Paper presented at the International Conference on Harmonization, Geneva.

Lamie, N. T. (2015). Comparative study of spectrophotometric methods manipulating ratio spectra: An application on pharmaceutical binary mixture of cinnarizine and dimenhydrinate. Spectrochimica Acta Part A: Molecular and Biomolecular Spectroscopy, 141, 193-201.

Liu, H., Wang, H., \& Sunderland, V. B. (2005). An isocratic ion exchange HPLC method for the simultaneous determination of flucloxacillin and amoxicillin in a pharmaceutical formulation for injection. Journal of pharmaceutical and biomedical analysis, 37(2), 395-398.

M.J. O'Neil. ( 2006). The Merck Index: An Encyclopedia of Chemicals, 14 th ed. Merck,. Drugs and Biologicals.

Mohamed, A. E.-M. I., Salem, H., \& Maher, E. (2007). Chemometrics-assisted spectrophotometric determination of certain $\beta$-lactam antibiotics combinations. Thai J. Pharm. Sci, 31, 9-27.

Nikam, D. S., Bonde, C. G., Surana, S., Venkateshwarlu, G., \& Dekate, P. (2009). Development and validation of RP-HPLC method for simultaneous estimation of amoxicillin trihydrate and flucloxacillin sodium in capsule dosage form. Int. J. Pharm. Tech. Res, 1(3), 935-939.

S.C. Sweetman, M. (2002.). The Complete Drug Reference, 33rd ed. Pharmaceutical Press,.

Sebaiy, M. M., El-Shanawany, A. A., El-Adl, S. M., Abdel-Aziz, L. M., \& Hashem, H. A. (2011). Rapid RP-HPLC method for simultaneous estimation of 
norfloxacin and tinidazole in tablet dosage form. Asian Journal of Pharmaceutical Analysis, 1(4), 79-84.

Shanmugasundaram, P., Raj, R. K., Mohanrangan, J., Devdass, G., Arunadevi, M., Maheswari, R., \& Aanandhi, M. V. (2009). Simultaneous estimation of amoxicillin and flucloxacillin in its combined capsule dosage form by HPLC. Rasayan J Chem, 2(1), 57-60.

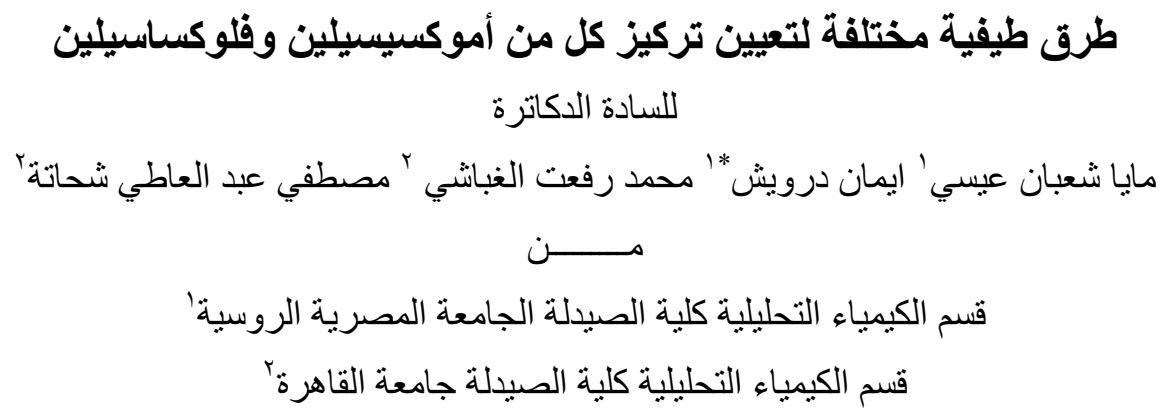

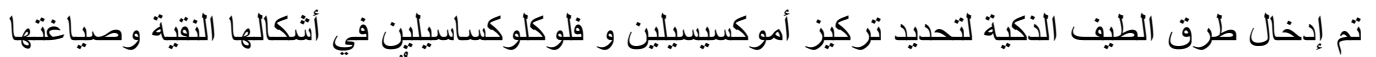

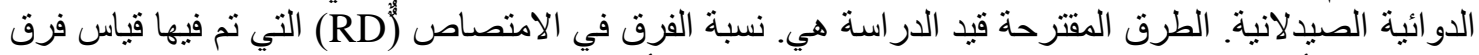

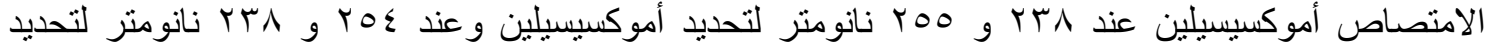

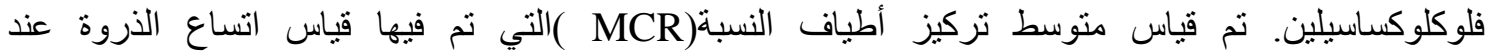

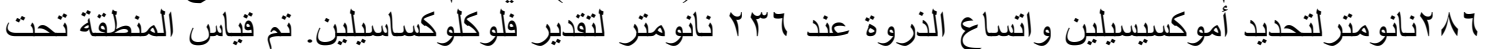

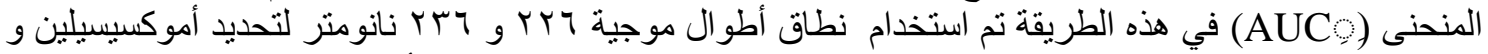
في • .

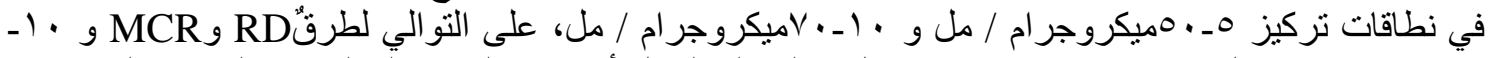

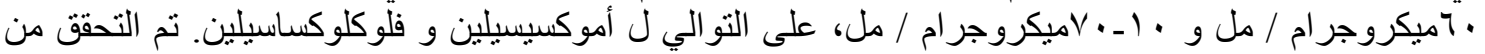

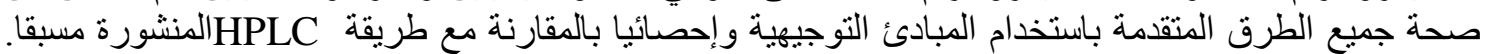
ويمكن تطبيق الأساليب المعتمدة للتحليل المنتظم للخليط اموكسيسلين وفلوكساسيلين في مختبر ات مر اقبة الجودة. 